\title{
Atherosclerotic Renovascular Disease and Renal Impairment: Can We Predict the Effect of Intervention?
}

\author{
Kwok-Wai Mui, MD, Arend-Jan Woittiez, MD, PhD, \\ and Gerjan Navis, $M D, P h D$
}

\author{
Corresponding author \\ Gerjan Navis, MD, PhD \\ Division of Nephrology, Department of Medicine, University \\ Medical Center Groningen, PO Box 30001, 9700 RB Groningen, \\ The Netherlands. \\ E-mail: g.j.navis@int.umcg.nl \\ Current Hypertension Reports 2007, 9:140-147 \\ Current Medicine Group LLC ISSN 1522-6417 \\ Copyright $(0) 2007$ by Current Medicine Group LLC
}

Atherosclerotic renal artery stenosis (ARAS) is associated with hypertension, ischemic nephropathy, and high cardiovascular risk. We review the data on revascularization of the renal artery by percutaneous transluminal renal angioplasty (PTRA) and pharmacological therapy. In patients with severe ARAS and poorly controlled hypertension, PTRA can improve blood pressure control. In patients with rapid renal function loss and severe ARAS, PTRA can improve short-term renal function, but there is no evidence for long-term renoprotection. Recent evidence indicates that ARAS, and incidental renal artery stenosis, considerably increases cardiovascular risk, independent of blood pressure, renal function, and prevalent risk factors. This suggests that revascularization might potentially improve overall prognosis, but no data are available currently. The high cardiovascular risk warrants aggressive pharmacological treatment to prevent progression of the generalized vascular disorder. Ongoing trials will show whether revascularization has added, long-term effects on blood pressure, renal function, and cardiovascular prognosis.

\section{Introduction}

Atherosclerotic renal artery stenosis (ARAS) is associated with hypertension, ischemic nephropathy, cardiovascular disease [1,2], and a twofold to fivefold increase in cardiovascular mortality [3-5]. Furthermore, ARAS is assumed to account for $5 \%$ to $15 \%$ [6], or even $25 \%$ of new cases of end-stage renal failure [7]. The exact prevalence of
ARAS in the general population is unknown because many cases remain undetected. In autopsies conducted after stroke [8] and myocardial infarction [9], the prevalence of ARAS was $10.4 \%$ and $12 \%$, respectively. In a community-based screening for cardiovascular disease and risk factors from the United States, a prevalence of $6.8 \%$ was reported in elderly subjects with a mean age of 77 years [10]. Clinical studies report widely different prevalences in populations with different clinical conditions. In hypertensive subjects the prevalence of ARAS is less than $1 \%$ in unselected populations, whereas it is $5 \%$ in hospital-based populations, and up to $40 \%$ in thirdline referral clinics [11,12]. Among patients starting dialysis, the prevalence of ARAS was $31 \%$ in women and $22 \%$ in men [13]. Finally, ARAS is frequently encountered as an incidental finding in patients who undergo routine angiography for peripheral vascular disease (PVD) or coronary artery disease; in these populations prevalence ranges from $5 \%$ to $40 \%$ [14-17,18•].

The treatment of ARAS has been a matter of dispute for a long time. In ARAS, as opposed to fibromuscular dysplasia, the narrowing of the renal artery is not an isolated phenomenon, but is part of a process of generalized atherosclerosis. The Goldblatt phenomenon, which attributes the driving force of the pathophysiologic events to increased activity of the renin-angiotensin system due to perfusion impairment in the post-stenotic kidney, may reflect relatively well the pathophysiologic mechanisms in experimental models and in renal artery stenosis (RAS) due to fibromuscular dysplasia, and is substantiated by the therapeutic benefits of revascularization by percutaneous transluminal renal angioplasty (PTRA) or surgery in this condition [19]. However, in ARAS the narrowing of the renal artery is not an isolated phenomenon, but part of a progressive process of generalized atherosclerosis. The impact of anatomical abnormalities in the renal artery as a driving force in the elevated, multi-organ cardiovascular risk in these patients, relative to other mechanisms of end-organ damage, is uncertain. It would seem logical to aim at revascularization of the kidney, 
because this has the appeal of a causal intervention. Along this line of reasoning, several controlled trials demonstrated that PTRA can indeed lower blood pressure and may prevent clinical events such as progressive renal failure [6]. The benefits and particularly the risks of intervention have not been well defined, however, and prospective randomized data that also consider longterm outcome are lacking.

On the other hand, there is increasing awareness that ARAS occurs in the context of generalized atherosclerosis. Based on current guidelines for hypertension [20,21], the high risk in patients with ARAS warrants aggressive treatment of the prevalent cardiovascular risk factors (eg, hypertension, hypercholesterolemia, glycemia) in all patients with ARAS. Possible benefits of revascularization thus should outweigh those of optimal conservative intervention, and the possible benefit should be weighed against the risks of revascularization for individual patients. However, it should also be noted that in patients with ARAS, the risk for cardiovascular morbidity and mortality is greater than explained by blood pressure alone [1] and, remarkably, the presence of RAS in itself is an independent risk factor for cardiovascular morbidity and mortality $[17,18 \bullet]$. This raises the intriguing possibility that revascularization may contribute to improvement of overall outcome in high-risk subjects, even independent of blood pressure $[18 \bullet, 22]$.

In this article we provide an overview of the available data on outcome of revascularization on top of (optimal) pharmacological therapy in ARAS on blood pressure, renal function, and prevention of cardiovascular events, and address the question whether the therapeutic effect of revascularization can be predicted, in order to be able to select the patients with ARAS who are likely to benefit from revascularization.

\section{PTRA: Effects on Blood Pressure}

Two types of revascularization procedures are available currently: PTRA with or without stenting, and surgical reconstruction. PTRA is currently the first choice because it is less invasive. Randomized data in patients with ostial ARAS showed that PTRA is as effective as surgical reconstruction, and moreover, a simpler procedure [23]. A recent meta-analysis of randomized controlled trials addressed the antihypertensive effect of balloon angioplasty versus standard medical therapy in ARAS [24]. The literature search identified three published clinical randomized trials: the EMMA trial [25]; the SNRASCG trial [26]; and the DRASTIC trial [27]. Altogether there were 210 patients in the three trials with moderate to severe $(\geq 50 \%)$ unilateral or bilateral ARAS and poorly controlled hypertension who were followed for at least 3 months (longest follow-up, 12 months) after intervention. The pooled data using the 3-month follow-up values from the DRASTIC trial and the 6-month data from the two other trials showed a significantly greater decrease in both systolic and diastolic blood pressure from baseline in the angioplasty group as compared with medical therapy. The weighted mean difference between the two treatments was $-7 \mathrm{~mm} \mathrm{Hg}$ (95\% CI: -12 to $-1 \mathrm{~mm} \mathrm{Hg}$ ) for systolic blood pressure and $-3 \mathrm{~mm} \mathrm{Hg}$ (95\% CI: -6 to $-1 \mathrm{~mm} \mathrm{Hg}$ ) for diastolic blood pressure. Patients treated with balloon angioplasty (DRASTIC trial) were more likely to have patent renal arteries after 12 months $(52 \%$ vs $19 \%$; odds ratio $=4.2 ; 95 \%$ CI: 1.8 to 9.8$)$, and had a significant decrease in median defined daily doses, in the EMMA trial at 6 months $(P=0.009)$, whereas in the DRASTIC trial at 3 months $(P<0.001)$. The number of antihypertensive drugs was also significantly lower in the balloon angioplasty group at both 3 and 12 months in the DRASTIC trial. This allows us to conclude that balloon angioplasty on top of standard medical therapy has a modest but significant effect on blood pressure compared to medical therapy alone. Unfortunately, to date there are no randomized studies comparing renal artery stenting to medication.

In a trial comparing PTRA plus stenting (PTRAS) to PTRA alone [28], PTRAS seemed to be a better technique than PTRA to achieve vessel patency in ostial ARAS. However, the two procedures did not differ in their effects on blood pressure outcome after 6 months of follow-up.

\section{PTRA: Effects on Renal Function}

The natural course of the rate of renal function decline in patients with ARAS is uncertain. Progression of renal failure in patients with ARAS may reflect progression in the degree of narrowing of the renal artery, progression associated with ischemic nephropathy, or both. Rimmer and Gennari [6] reviewed five reports concerning serial angiograms in 237 patients with ARAS. Progression, including worsening of existing stenosis of the renal artery or the development of contralateral RAS, was reported in 116 patients (49\%) during follow-up periods of 6 to 18 months. Renal artery occlusion occurred in 28 cases $(14 \%)$. In another report, the 3 -year cumulative incidence of progression, defined as any detectable increase in the degree of diameter reduction affecting at least one renal artery, was $35 \%$ [29]. In a stepwise Cox proportional hazard analysis, baseline risk factors associated with progression were a systolic blood pressure of at least $160 \mathrm{~mm}$ $\mathrm{Hg}$, diabetes mellitus, and high-grade $(\geq 60 \%$ stenosis, or occlusion) ipsilateral or contralateral stenosis [29]. Thus far, the available randomized controlled trials focused on the effect of PTRA (on top of medical therapy) versus medical therapy alone on blood pressure [25-27]. The EMMA, SNRASCG, and DRASTIC studies are summarized in Table 1 . The studies separately did not show improvement of renal function.

Because the lack of effect might be due to the limited power of the separate studies, due to their limited size 


\begin{tabular}{|c|c|c|c|c|c|}
\hline Study & $\begin{array}{c}\text { Intervention, number of } \\
\text { patients, } n \text {, mean follow-up, mo }\end{array}$ & $\begin{array}{c}\text { Bilateral stenosis, } \\
n(\%)\end{array}$ & Renal function & Baseline & $\begin{array}{c}\text { Outcome } \\
\text { (significance) }\end{array}$ \\
\hline \multicolumn{6}{|l|}{ Randomized } \\
\hline \multirow[t]{2}{*}{ Plouin et al. [25] } & $\begin{array}{c}\text { Medication (standard), } \\
\quad n=26(6 \mathrm{mo})\end{array}$ & None & eGFR* & $73.2 \mathrm{~mL} / \mathrm{min}$ & $+0.6 \mathrm{~mL} / \mathrm{min}(\mathrm{NS})$ \\
\hline & PTRA, $n=23$ & & & $73.2 \mathrm{~mL} / \mathrm{min}$ & $+3.6 \mathrm{~mL} / \mathrm{min}(\mathrm{NS})$ \\
\hline \multirow[t]{4}{*}{$\begin{array}{l}\text { Webster } \\
\text { et al. [26] }\end{array}$} & $\begin{array}{l}\text { Medication (standard), } \\
\quad n=14(3-54 \mathrm{mo})\end{array}$ & None & Serum creatinine & $1.87 \mathrm{mg} / \mathrm{dL}$ & No change \\
\hline & PTRA, $n=13$ & & & $1.53 \mathrm{mg} / \mathrm{dL}$ & + $0.09 \mathrm{mg} / \mathrm{dL}(\mathrm{NS})$ \\
\hline & Medication, $n=16$ & $28(100 \%)$ & & $1.64 \mathrm{mg} / \mathrm{dL}$ & $+0.04 \mathrm{mg} / \mathrm{dL}(\mathrm{NS})$ \\
\hline & PTRA, $n=12$ & & & $2.02 \mathrm{mg} / \mathrm{dL}$ & $+0.11 \mathrm{mg} / \mathrm{dL}(\mathrm{NS})$ \\
\hline \multirow[t]{2}{*}{$\begin{array}{l}\text { van Jaarsveld } \\
\text { et al. [27] }\end{array}$} & $\begin{array}{l}\text { Medication (standard), } \\
\quad n=50(12 \mathrm{mo})\end{array}$ & $24(23 \%)$ & eGFR* & $60 \mathrm{~mL} / \mathrm{min}$ & 62 mL/min (NS) \\
\hline & PTRA, $n=56$ & & & $67 \mathrm{~mL} / \mathrm{min}$ & 70 mL/min (NS) \\
\hline \multicolumn{6}{|l|}{ Nonrandomized } \\
\hline \multirow{3}{*}{$\begin{array}{l}\text { La Batide-Alanore } \\
\text { et al. }[30 \bullet]\end{array}$} & PTRA, $n=18(6 \mathrm{mo})$ & None & Total GFR & $83 \mathrm{~mL} / \mathrm{min}$ & $+3 \mathrm{~mL} / \mathrm{min}(\mathrm{NS})$ \\
\hline & & & $\begin{array}{l}\text { GFR stenotic } \\
\text { kidney }\end{array}$ & $32 \mathrm{~mL} / \mathrm{min}$ & $\begin{array}{r}+6 \mathrm{~mL} / \mathrm{min} \\
(P<0.001)\end{array}$ \\
\hline & & & $\begin{array}{l}\text { GFR nonstenotic } \\
\text { kidney }\end{array}$ & $51 \mathrm{~mL} / \mathrm{min}$ & $\begin{array}{l}-4 \mathrm{~mL} / \mathrm{min} \\
(P<0.001)\end{array}$ \\
\hline \multirow[t]{2}{*}{ Beutler et al. [31] } & $\begin{array}{c}\text { PTRAS, stable creatinine, } \\
\quad n=26(12 \mathrm{mo})\end{array}$ & $21(33 \%)$ & Serum creatinine & $1.72 \mathrm{mg} / \mathrm{dL}$ & $+0.04 \mathrm{mg} / \mathrm{dL}(\mathrm{NS})$ \\
\hline & $\begin{array}{l}\text { PTRAS, deteriorating } \\
\text { creatinine, } n=30\end{array}$ & & & $2.02 \mathrm{mg} / \mathrm{dL}$ & $\begin{array}{r}-0.31 \mathrm{mg} / \mathrm{dL} \\
(P<0.036)\end{array}$ \\
\hline \multirow[t]{4}{*}{ Roussos et al. [33] } & $\begin{array}{l}\text { PTRA, with deteriorating } \\
\text { creatinine, } n=48 \text { ( } 12 \mathrm{mo})\end{array}$ & $11(23 \%)$ & $\mathrm{eGFR}^{+}$ & $23 \mathrm{~mL} / \mathrm{min}$ & $\begin{array}{r}+7 \mathrm{~mL} / \mathrm{min} \\
(P=0.072)\end{array}$ \\
\hline & $\begin{array}{c}\text { PTRA, with accelerating } \\
\mathrm{HT}, n=47\end{array}$ & $10(21 \%)$ & & $37 \mathrm{~mL} / \mathrm{min}$ & $+1 \mathrm{~mL} / \min (\mathrm{NS})$ \\
\hline & $\begin{array}{l}\text { PTRA, with renal } \\
\text { failure }+\mathrm{HT}, n=25\end{array}$ & $7(28 \%)$ & & $29 \mathrm{~mL} / \mathrm{min}$ & $+2 \mathrm{~mL} / \min (\mathrm{NS})$ \\
\hline & PTRA, with PVD, $n=24$ & $5(21 \%)$ & & $29 \mathrm{~mL} / \mathrm{min}$ & $+1 \mathrm{~mL} / \min (\mathrm{NS})$ \\
\hline \multicolumn{6}{|c|}{$\begin{array}{l}\text { *eGFR estimated with use of Cockcroft-Gault formula }\left(\mathrm{mL} / \mathrm{min} \text { per } 1.73 \mathrm{~m}^{2}\right) \text {. } \\
\text { +eGFR estimated with abbreviated version of MDRD equation }\left(\mathrm{mL} / \mathrm{min} \text { per } 1.73 \mathrm{~m}^{2}\right) \text {. } \\
\text { eGFR-estimated glomerular filtration rate; GFR_-glomerular filtration rate; HT_hypertension; NS—not significant; PTRA—percutaneous } \\
\text { transluminal renal angioplasty; PTRAS—PTRA plus stenting; PVD—peripheral vascular disease. }\end{array}$} \\
\hline
\end{tabular}

and relatively short follow-up, the previously mentioned meta-analysis [24] tried to combine the results of the three studies to see whether intervention could actually improve renal function outcome. However, because the effect on renal function was measured in different ways, the results could not be pooled.

The fact that there was no improvement of renal function, despite anatomically successful revascularization, may be explained in several ways. First, the patients included in these studies all had relatively normal renal function (EMMA and DRASTIC studies) or only mild renal insufficiency (SNRASCG study), so any improvement could be small as well and thus difficult to detect. Second, the specific pathophysiology of renal function impairment in ARAS should be taken into account. In unilateral ARAS glomerular filtration rate (GFR) does not reflect individual kidney function, because hyperfiltration in the normal kidney may compensate for reduced filtration in the ischemic kidney.

Moreover, renal failure may result from both ischemia of the stenotic kidney, resulting in progressive renal fibrosis and atrophy, and hypertensive nephropathy in the contralateral kidney. In the stenotic kidney, both in unilateral and bilateral RAS, chronic ischemia may eventually result in irreversible damage to the renal parenchyma, so that dilating the stenotic lesion is no more than a "cosmetic" intervention. In this respect, $\mathrm{La}$ Batide-Alanore et al. [30•] evaluated split renal function (SRF, estimated by technetium ${ }^{99 \mathrm{~m}} \mathrm{Tc}$-diethylenetriamine penta-acetic acid scintigraphy) outcome after PTRA in patients with unilateral 
RAS ( $\geq 60 \%$ ). They prospectively evaluated SRF and total GFR (clearance methods) after successful PTRA in 32 consecutive hypertensive patients with RAS (18 atherosclerotic and 14 with dysplastic disease) and a total GFR of at least $60 \mathrm{~mL} / \mathrm{min}$ per $1.73 \mathrm{~m}^{2}$. Six months after successful PTRA, single-kidney GFR of the stenotic kidney had increased significantly, whereas concurrent single-kidney GFR of the nonstenotic kidney decreased significantly (Table 1). Thus, reversal of both the hypoperfusion of the stenotic side and the hyperperfusion of the nonstenotic side was observed, with a slight increase in total GFR as a net result. This elegant study nicely demonstrates that "early" successful revascularization of unilateral RAS (at least in patients with normal GFR) can facilitate restoration of the normal distribution of renal blood flow, and hence renal function, between the two kidneys. This presumably protects the stenotic kidney from ischemia, and the contralateral kidney from hyperfiltration that may contribute to long-term renal parenchymal damage, especially in the presence of systemic hypertension. However, it should be emphasized that randomized prospective trials are required to confirm the longterm beneficial effects of the establishment of a new equilibrium after PTRA on prevention of further renal function deterioration.

Although randomized studies are still lacking, several nonrandomized studies showed improvement or even delay of dialysis after PTRA (with or without stenting) in patients with ARAS and severe renal dysfunction (Table 1). Beutler et al. [31] demonstrated that in patients with pre-stent declining renal function (an increase in serum creatinine of $\geq 20 \%$ in 12 months), PTRAS improved median serum creatinine in the first year (from $2.02 \mathrm{mg} / \mathrm{dL}$ [1.5 to $3.0 \mathrm{mg} / \mathrm{dL}$ ] to $1.71 \mathrm{mg} / \mathrm{dL}$ [ 1.4 to $2.5 \mathrm{mg} / \mathrm{dL}$; $P<0.05)$ and remained stable during further follow-up monitoring (12 months after stent placement). The treatment had no effect on serum creatinine levels if function had previously been stable. Similar results were reported by Korsakas et al. [32] in 28 patients with a serum creatinine greater than $3.33 \mathrm{mg} / \mathrm{dL}$, and progressive loss of renal function at least 1 year before angioplasty, in whom PTRA (with or without stent) significantly slowed progression of renal failure. A favorable outcome was correlated with a lower creatinine level $(P=0.0137)$ and a more rapid prior loss of renal function $(r=0.49$, $P=0.020$ ) at entry. Roussos et al. [33] showed that patients with ARAS who were referred for angioplasty because of deteriorating renal function (mean serum creatinine: 3.66 $\pm 1.89 \mathrm{mg} / \mathrm{dL}$ ) had a small increase in glomerular filtration rate at 3 -month follow-up (from $23 \pm 11$ to $27 \pm 14 \mathrm{~mL}$ / $\left.\min / 1.73 \mathrm{~m}^{2} ; P=0.021\right)$. Analysis with patients who had both renal function deterioration and accelerated hypertension showed improvement of glomerular filtration rate (from $25 \pm 11$ to $28 \pm 14 \mathrm{~mL} / \mathrm{min} / 1.73 \mathrm{~m}^{2} ; P=0.031$ ) 3 months after intervention. However, no statistically significant difference was found 1 year after angioplasty.
Several studies attempted to identify reliable predictors of renal function outcome after revascularization. Halimi et al. [34] reported that the effect of intervention (PTRA, $n=5$; or surgery, $n=18$ ) in a small heterogeneous group of ARAS patients was associated with pre-intervention albuminuria. On stepwise regression analysis, pre-intervention urinary albumin excretion was the only predictor of the response of renal function to intervention, with lack of improvement in albuminuric subjects. This suggests that, in ARAS, albuminuria is a marker of intrarenal parenchymal damage that is not responsive to revascularization. This is in accord with data reported by Campo et al. [35] in 52 patients, who reported better outcome in renal function decline after PTRA in patients with proteinuria less than $1 \mathrm{~g} / \mathrm{day}$, serum creatinine less than $4 \mathrm{mg} / \mathrm{dL}$, and low resistance index, respectively. In this study, neither kidney size nor rapid prior renal function deterioration predicted outcome after PTRA. A high resistance index, as assessed by Doppler ultrasonography, was also found to be a predictor of worse outcome after PTRA for blood pressure and renal function in the study by Radermacher et al. [36] in 138 ARAS patients. Unfortunately, however, many patients with ARAS are obese and thus not easily accessible for reliable Doppler sonography; moreover, the technique is relatively observer-dependent. The finding of a small kidney size $(<8 \mathrm{~cm})$ is considered a sign of renal failure, and PTRA on such small kidneys should not be undertaken, because it is unlikely that the risks outweigh the benefits-with the exception of ARAS patients entering dialysis programs. Despite small-sized (but not shrunken) kidneys, several patients could discontinue dialysis after PTRA [37]. Krijnen et al. [38] analyzed data from the DRASTIC study, and found that patients with bilateral stenosis benefit the most from immediate angioplasty with regard to renal function and blood pressure after 1 year of follow-up.

In summary, data on the impact of PTRA on renal function are relatively sparse, and limited mainly to short-term studies. Whereas apparently PTRA can favorably affect overall renal function, such an effect is usually absent in subjects with stable renal function, or in those in whom irreversible parenchymal damage is present, as suggested by stable moderate to severe renal function impairment or albuminuria. Current data indicate that improvement of kidney function after renal vascularization (added to standard medical therapy) may be expected in patients with rapid deterioration of renal function in the year or months before intervention, in whom renal function is nevertheless still relatively well preserved at the time of intervention. In selected cases, revascularization can result in renal function improvement even in patients in whom rapid renal function deterioration is so severe as to necessitate dialysis, as shown by case reports and Korsakas et al. [32]. In patients with normal to mildly impaired stable renal function, especially patients with unilateral RAS, 


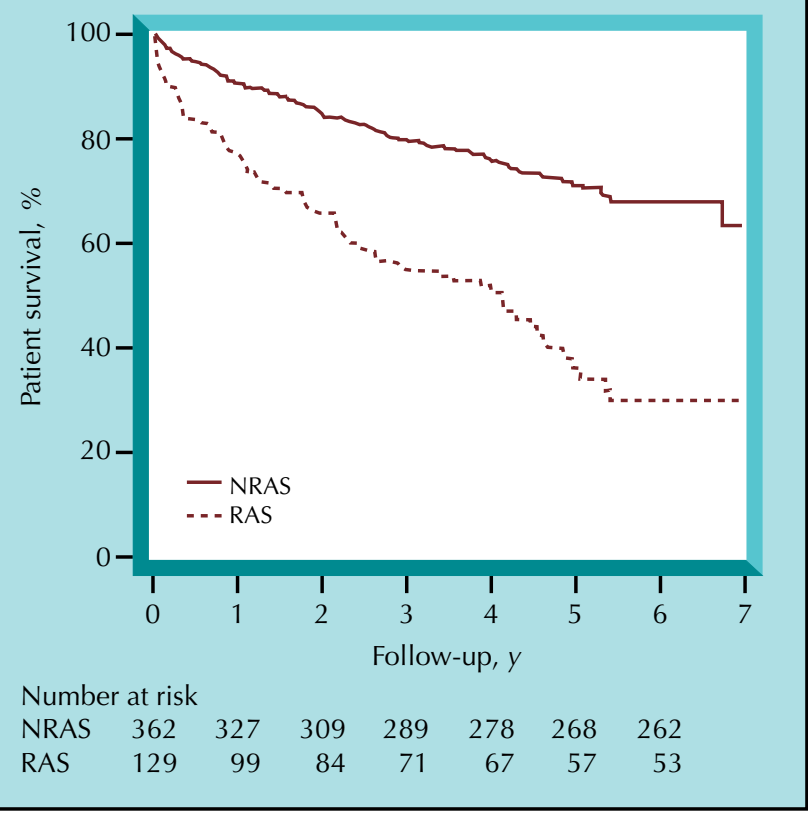

Figure 1. Kaplan-Meier survival plots for 491 patients with peripheral vascular disease, comparing outcomes for those with incidentally discovered renal artery stenosis (RAS) and those without renal artery stenosis (NRAS). On Cox regression analysis, the elevated risk for mortality in RAS was independent of blood pressure, renal function, and other cardiovascular risk factors.

one cannot expect improvement of kidney function and the effect of revascularization for the long-term prognosis is uncertain.

\section{PTRA: Effects on Prevention of Cardiovascular Events and Mortality}

There are no randomized clinical trials evaluating the comparative effects of renal artery revascularization with medical therapy on cardiovascular morbidity and mortality in patients with ARAS, with or without co-morbid conditions [22]. Yet, in patients with ARAS the risk for premature cardiovascular death considerably exceeds their risk for progression to end-stage renal failure. The risk is particularly elevated in patients with lower baseline renal function, which was reported to predict mortality after PTRA [39].

This elevated risk was demonstrated recently by Kalra et al. [1] in a large randomly selected population cohort $(n=1,085,250)$ and an essentially similar picture emerges for patients with incidental RAS. Leertouwer et al. [15] showed that during 10 years of follow-up, if left untreated, incidental RAS did not lead to end-stage renal failure or the need for renal replacement therapy. Thus, revascularization is not recommended in incidentally discovered RAS $[14,15]$. However, the risk of cardiovascular mortality is considerably increased, as demonstrated in a cohort of 491 patients with peripheral vascular disease, where incidental RAS was associated with an increased prevalence of not only kidney disease but also mortality (Fig. 1) [18•]. Cox regression analysis showed that RAS was an independent predictor of mortality $(P=0.005)$, along with age, diabetes, smoking, previous myocardial infarction, and stroke. Interestingly, inclusion of RAS in the multivariate analysis abolished the effects of hypertension and renal function on mortality. Thus incidentally found RAS is a marker of poor prognosis. This is partly explained by its close association with extended cardiovascular disease, as well as with many established risk factors, such as older age $[18 \bullet, 40]$, impaired renal function [18], hypertension $[18 \bullet, 41]$, history of coronary artery disease $[17,18 \bullet, 40]$ and diabetes $[18 \bullet, 41]$. However, in the above population with PVD, the increased risk for mortality could not be explained fully by these factors, which accords with data from patients who undergo diagnostic cardiac catheterization simultaneously with an aortography, in whom incidental RAS was an independent risk factor for mortality [17,42].

Moreover, the severity of RAS was related to mortality. Whether the independent association between (incidental) ARAS and cardiovascular mortality implicates a causal effect has not been established, but it is conceivable that neurohumoral activation from the ischemic kidney exerts unfavorable cardiovascular effects. If so, revascularization may have the potential to improve cardiovascular prognosis, even in incidental ARAS - as has been suggested for heart failure patients with ARAS [22]. Such studies, however, have not been performed. At any rate, from the point of view of their high risk profile, all patients with (incidental) ARAS should receive optimal pharmacological and supportive treatment to manage their cardiovascular risk, in compliance with current guidelines. It is known that rigorous treatment of hypertension and strict regulation of diabetes improve cardiovascular morbidity and mortality [43-45] and that an intensive (supraoptimal) regimen of lipid-lowering statin drugs can improve prognosis in high-risk populations, especially in patients with coronary artery disease and metabolic syndrome [46,47]. It would be of interest to test such strategies in patients with ARAS.

\section{Future Studies}

Currently, four large randomized intervention trials are ongoing, with defined clinical endpoints as summarized in Table 2. The primary endpoint of the three ongoing trials from Europe is the kidney function. The STAR trial aims to compare the effects of renal artery stent placement together with optimal medication versus optimal medication alone on renal function in ARAS patients [48]. Patients are followed for 2 years with extended follow-up to 5 years. The primary outcome of this study is a reduction in creatinine clearance greater than $20 \%$ compared to baseline. This trial will include 140 patients. 


\begin{tabular}{|c|c|c|c|c|}
\hline $\begin{array}{l}\text { Randomized } \\
\text { study }\end{array}$ & $\begin{array}{l}\text { Intervention, number of intended } \\
\text { patients, } n \text {, follow-up, } y\end{array}$ & Primary endpoint & Start study & Data available \\
\hline Bax et al. [48] & $\begin{array}{l}\text { PTRAS (on top of optimal medication*) } \\
\text { vs optimal medication, } n=140,2 y \text {, } \\
\text { extended to } 5 \mathrm{y}\end{array}$ & $\begin{array}{l}\text { Reduction in creatinine } \\
\text { clearance }>20 \% \\
\text { compared to baseline }\end{array}$ & June 2000 & Inclusion ended in 2006 \\
\hline Scarpioni et al. [49] & $\begin{array}{l}\text { PTRAS (on top of optimal medication*) } \\
\text { vs optimal medication, } n=100,2 y \text {, } \\
\text { extended to } 4 \mathrm{y}\end{array}$ & $\begin{array}{l}\text { Death or dialysis } \\
\text { initiation or reduction } \\
\text { by }>20 \% \text { in eGFR } \\
\text { compared to baseline }\end{array}$ & January 2003 & $\begin{array}{l}\text { Last enrollment: } \\
\text { January } 2007\end{array}$ \\
\hline ASTRAL [50] & $\begin{array}{l}\text { PTRAS (standard medication) vs } \\
\text { medication (standard), } n=750 \text { (min), } \\
1 \mathrm{y} \text {, extended to } 5 \mathrm{y}\end{array}$ & $\begin{array}{l}\text { Mean slope of the } \\
\text { reciprocal creatinine } \\
\text { plot vs time }\end{array}$ & September 2000 & $\begin{array}{l}\text { Last enrollment: April } \\
2007 \text { (641 patients } \\
\text { included March 2006) }\end{array}$ \\
\hline Cooper et al. [51] & $\begin{array}{l}\text { PTRAS (on top of optimal medication }{ }^{\dagger} \text { ) } \\
\text { versus optimal medication, } \\
n=1080,2 \text { y }\end{array}$ & $\begin{array}{l}\text { Event-free survival } \\
\text { from CV and renal } \\
\text { adverse events }\end{array}$ & 2005 & $\begin{array}{l}\text { Last enrollment: } \\
\text { December } 2006 \text { (last } \\
\text { follow-up contact: 2009) }\end{array}$ \\
\hline \multicolumn{5}{|c|}{$\begin{array}{l}\text { *Optimal medication: statins, antihypertensive drugs, and antiplatelet therapy. } \\
{ }^{*} \text { Optimal medication: first-line drug angiotensin II type } 1 \text { receptor antagonist, other therapy according to JNC } 7 \text { report. } \\
\text { CV_-cardiovascular; eGFR_-estimated glomerular filtration rate; JNC } 7 \text {-Seventh Report of Joint National Committee on Prevention, Detection, } \\
\text { Evaluation, and Treatment of High Blood Pressure; PTRA—-percutaneous transluminal renal angioplasty; PTRAS—PTRA plus stenting. }\end{array}$} \\
\hline
\end{tabular}

The NITER trial aims to evaluate whether medical therapy plus interventional PTRAS is superior to medical therapy alone according to the following combined primary endpoint: death or dialysis initiation or reduction by greater than $20 \%$ in estimated GFR after $0.5,1$, and 2 years of follow-up and an extended follow-up until the fourth year [49]. The sample size is estimated in 50 patients per group to achieve a statistical significance of 0.05 in case of a reduction by $50 \%$ in the combined endpoints.

The ASTRAL study is the largest trial, with the intention to include 1000 patients, and compares angioplasty (with or without stenting, on top of medical therapy, free of choice) with medical therapy (free of choice) [50]. The progress of patients will be followed for at least a year. The primary comparison is the rate of progression of renal failure, as assessed by reciprocal creatinine plots over the course of the trial. Secondary endpoints include blood pressure control and the occurrence of serious vascular events (eg, myocardial infarction and stroke).

The latest trial is from the United States, the CORAL trial [51]. Randomization will occur in 1080 subjects. Optimal medical therapy alone compared to stenting with optimal medical therapy on a composite cardiovascular and renal endpoint (cardiovascular or renal death, myocardial infarction, hospitalization for congestive heart failure, stroke, doubling of serum creatinine, and need for renal replacement therapy) will be studied. Hopefully, these studies have the potential to clarify the uncertainty concerning indications for, and outcomes after, renal revascularization in patients with ARAS.

\section{Conclusions}

ARAS is a condition associated with hypertension, renal function impairment, and a particularly high cardiovas- cular risk. This requires optimal medical therapy aimed at treatment of the prevalent cardiac risk factors in all ARAS patients. Revascularization on top of medical therapy can improve blood pressure control in patients with severe ARAS and poorly controlled hypertension. Short-term improvement in renal function has been reported, but at this time there is no evidence that early revascularization can prevent long-term loss of renal function. However, in individuals with rapidly progressing renal function loss and severe ARAS, PTRAS can improve renal function. Recent evidence indicates that ARAS-and interestingly, incidental RAS-is associated with cardiovascular risk, also independent from blood pressure, renal function, and prevalent cardiovascular risk factors. This suggests that revascularization may have the potential to improve overall cardiovascular prognosis. Ongoing randomized trials in ARAS address the long-term effects of revascularization, on top of pharmacological intervention, on blood pressure, renal function, and mortality. It is hoped that these trials will provide us with data that can guide clinical decision making in this grim condition.

\section{Clinical Trial Acronyms}

ASTRAL-Angioplasty and Stent for Renal Artery Lesions; CORAL-Cardiovascular Outcomes in Renal Atherosclerotic Lesions; DRASTIC—Dutch Renal Artery Stenosis Intervention Cooperative; EMMA-Essai Multicentrique Medicaments vs Angioplastie; NITERNephropathy Ischemic Therapy; SNRASCG-Scottish and Newcastle Renal Artery Stenosis Collaborative Group; STAR-Benefit of Stent Placement and Blood Pressure and Lipid-lowering for the Prevention of Progression of Renal Dysfunction Caused by Atherosclerotic Ostial Stenosis of the Renal Artery. 
References and Recommended Reading

Papers of particular interest, published recently, have been highlighted as:

- Of importance

$\bullet \quad$ Of major importance

1. Kalra PA, Guo H, Kausz AT, et al.: Atherosclerotic renovascular disease in United States patients aged 67 years or older: risk factors, revascularization, and prognosis. Kidney Int 2005, 68:293-301.

2. Wright JR, Shurrab AE, Cooper A, et al.: Left ventricular morphology and function in patients with atherosclerotic renovascular disease. J Am Soc Nephrol 2005, 16:2746-2753.

3. Johansson M, Herlitz H, Jensen G, et al.: Increased cardiovascular mortality in hypertensive patients with renal artery stenosis. Relation to sympathetic activation, renal function and treatment regimens. J Hypertens 1999, 17:1743-1750.

4. Isles C, Main J, O'Connell J, et al.: Survival associated with renovascular disease in Glasgow and Newcastle: a collaborative study. Scott Med J 1990, 35:70-73.

5. Wright JR, Shurrab AE, Cheung C, et al.: A prospective study of the determinants of renal functional outcome and mortality in atherosclerotic renovascular disease. Am J Kidney Dis 2002, 39:1153-1161.

6. Rimmer JM, Gennari FJ: Atherosclerotic renovascular disease and progressive renal failure. Ann Intern Med 1993, 118:712-719.

7. Scoble JE: Atherosclerotic nephropathy. Kidney Int 1999, 71(Suppl):S106-S109.

8. Kuroda S, Nishida N, Uzu T, et al.: Prevalence of renal artery stenosis in autopsy patients with stroke. Stroke 2000 , 31:61-65.

9. Uzu T, Inoue T, Fujii T, et al.: Prevalence and predictors of renal artery stenosis in patients with myocardial infarction. Am J Kidney Dis 1997, 29:733-738.

10. Hansen KJ, Edwards MS, Craven TE, et al.: Prevalence of renovascular disease in the elderly: a population-based study. J Vasc Surg 2002, 36:443-451.

11. Derkx FH, Schalekamp MA: Renal artery stenosis and hypertension. Lancet 1994, 344:237-239.

12. Coen G, Calabria S, Lai S, et al.: Atherosclerotic ischemic renal disease. Diagnosis and prevalence in an hypertensive and/or uremic elderly population. BMC Nephrol 2003, 4:2.

13. Van Ampting JM, Penne EL, Beek FJ, et al.: Prevalence of atherosclerotic renal artery stenosis in patients starting dialysis. Nephrol Dial Transplant 2003, 18:1147-1151.

14. Iglesias JI, Hamburger RJ, Feldman L, Kaufman JS: The natural history of incidental renal artery stenosis in patients with aortoiliac vascular disease. Am J Med 2000, 109:642-647.

15. Leertouwer TC, Pattynama PM, van den Berg-Huysmans A: Incidental renal artery stenosis in peripheral vascular disease: a case for treatment? Kidney Int 2001, 59:1480-1483.

16. Pillay WR, Kan YM, Crinnion JN, Wolfe JH: Prospective multicentre study of the natural history of atherosclerotic renal artery stenosis in patients with peripheral vascular disease. Br J Surg 2002, 89:737-740.

17. Conlon PJ, Little MA, Pieper K, Mark DB: Severity of renal vascular disease predicts mortality in patients undergoing coronary angiography. Kidney Int 2001, 60:1490-1497.

18. Mui KW, Sleeswijk M, van den Hout H, et al.: Incidental renal artery stenosis is an independent predictor of mortality in patients with peripheral vascular disease. $\mathrm{J} \mathrm{Am} \mathrm{Soc} \mathrm{Nephrol}$ 2006, 17:2069-2074.

This study demonstrates that incidental RAS is associated with impaired kidney function and increased mortality in patients with PVD.

19. Slovut DP, Olin JW: Fibromuscular dysplasia. N Engl J Med 2004, 350:1862-1871.
20. Chobanian AV, Bakris GL, Black HR, et al.: The Seventh Report of the Joint National Committee on Prevention, Detection, Evaluation, and Treatment of High Blood Pressure: the JNC 7 report. JAMA 2003, 289:2560-2572.

21. Smith SC Jr, Allen J, Blair SN, et al.: AHA/ACC guidelines for secondary prevention for patients with coronary and other atherosclerotic vascular disease: 2006 update: endorsed by the National Heart, Lung, and Blood Institute. Circulation 2006, 113:2363-2372.

22. de Silva R, Nikitin NP, Bhandari S, et al.: Atherosclerotic renovascular disease in chronic heart failure: should we intervene? Eur Heart J 2005, 26:1596-1605.

23. Weibull H, Bergqvist D, Bergentz SE, et al.: Percutaneous transluminal renal angioplasty versus surgical reconstruction of atherosclerotic renal artery stenosis: a prospective randomized study. J Vasc Surg 1993, 18:841-850.

24. Nordmann AJ, Woo K, Parkes R, Logan AG: Balloon angioplasty or medical therapy for hypertensive patients with atherosclerotic renal artery stenosis? A meta-analysis of randomized controlled trials. Am J Med 2003, 114:44-50.

25. Plouin PF, Chatellier G, Darne B, Raynaud A: Blood pressure outcome of angioplasty in atherosclerotic renal artery stenosis: a randomized trial. Essai Multicentrique Medicaments vs Angioplastie (EMMA) Study Group. Hypertension 1998, 31:823-829.

26. Webster J, Marshall F, Abdalla M, et al.: Randomised comparison of percutaneous angioplasty vs continued medical therapy for hypertensive patients with atheromatous renal artery stenosis. Scottish and Newcastle Renal Artery Stenosis Collaborative Group. J Hum Hypertens 1998, 12:329-335.

27. van Jaarsveld BC, Krijnen P, Pieterman H, et al.: The effect of balloon angioplasty on hypertension in atherosclerotic renal-artery stenosis. Dutch Renal Artery Stenosis Intervention Cooperative Study Group. N Engl J Med 2000, 342:1007-1014.

28. van de Ven, Kaatee R, Beutler JJ, et al.: Arterial stenting and balloon angioplasty in ostial atherosclerotic renovascular disease: a randomised trial. Lancet 1999, 353:282-286.

29. Caps MT, Perissinotto C, Zierler RE, et al.: Prospective study of atherosclerotic disease progression in the renal artery. Circulation 1998, 98:2866-2872.

30. La Batide-Alanore A, Azizi M, Froissart M, et al.: Split renal function outcome after renal angioplasty in patients with unilateral renal artery stenosis. J Am Soc Nephrol 2001, 12:1235-1241.

This study nicely demonstrates that early successful revascularization of unilateral RAS can facilitate the restoration of the normal distribution of renal blood flow.

31. Beutler JJ, Van Ampting JM, van de Ven PJ, et al.: Long-term effects of arterial stenting on kidney function for patients with ostial atherosclerotic renal artery stenosis and renal insufficiency. J Am Soc Nephrol 2001, 12:1475-1481.

32. Korsakas S, Mohaupt MG, Dinkel HP, et al.: Delay of dialysis in end-stage renal failure: prospective study on percutaneous renal artery interventions. Kidney Int 2004, 65:251-258

33. Roussos L, Christensson A, Thompson O: A study on the outcome of percutaneous transluminal renal angioplasty in patients with renal failure. Nephron Clin Pract 2006, 104: c132-c142.

34. Halimi JM, Ribstein J, Du CG, et al.: Albuminuria predicts renal functional outcome after intervention in atheromatous renovascular disease. J Hypertens 1995, 13:1335-1342.

35. Campo A, Boero R, Stratta P, et al.: Selective stenting and the course of atherosclerotic renovascular nephropathy. J Nephroloy 2002, 15:525-529.

36. Radermacher J, Chavan A, Bleck J, et al.: Use of Doppler ultrasonography to predict the outcome of therapy for renal artery stenosis. N Eng J Med 2001, 344:410-417.

37. Haller C: Arteriosclerotic renal artery stenosis: conservative versus interventional treatment. Heart 2002, 88:193-197. 
38. Krijnen P, van Jaarsveld BC, Deinum J, et al.: Which patients with hypertension and atherosclerotic renal artery stenosis benefit from immediate intervention? J Hum Hypertens 2004, 18:91-96.

39. Dorros G, Jaff M, Matthiak L, et al.: Four-year follow-up of Palmaz Schatz stent revascularization as treatment for renal artery stenosis. Circulation 1998, 98:642-647.

40. Harding MB, Smith LR, Himmelstein SI, et al.: Renal artery stenosis: prevalence and associated risk factors in patients undergoing routine cardiac catheterization. $J \mathrm{Am}$ Soc Nephrol 1992, 2:1608-1616.

41. Missouris CG, Buckenham T, Cappuccio FP, MacGregor GA: Renal artery stenosis: a common and important problem in patients with peripheral vascular disease. $\mathrm{Am}$ J Med 1994, 96:10-14.

42. Conlon PJ, Athirakul K, Kovalik E, et al.: Survival in renal vascular disease. J Am Soc Nephrol 1998, 9:252-256.

43. Turnbull F: Effects of different blood-pressure-lowering regimens on major cardiovascular events: results of prospectively-designed overviews of randomised trials. Lancet 2003, 362:1527-1535.

44. UK Prospective Diabetes Study (UKPDS) Group: Intensive blood-glucose control with sulphonylureas or insulin compared with conventional treatment and risk of complications in patients with type 2 diabetes (UKPDS 33). Lancet 1998, 352:837-853.

45. Diabetes Control and Complications Trial Research Group: The effect of intensive treatment of diabetes on the development and progression of long-term complications in insulin-dependent diabetes mellitus. N Engl J Med 1993, 329:977-986.
46. Deedwania P, Barter P, Carmena R, et al.: Reduction of low-density lipoprotein cholesterol in patients with coronary heart disease and metabolic syndrome: analysis of the Treating to New Targets study. Lancet 2006, 368:919-928.

47. Cannon CP, Braunwald E, McCabe $\mathrm{CH}$, et al.: Intensive versus moderate lipid lowering with statins after acute coronary syndromes. N Engl J Med 2004, 350:1495-1504.

48. Bax L, Mali WP, Buskens E, et al.: The benefit of stent placement and blood pressure and lipid-lowering for the prevention of progression of renal dysfunction caused by atherosclerotic ostial stenosis of the renal artery. The STAR-study: rationale and study design. J Nephrol 2003, 16:807-812.

49. Scarpioni R, Michieletti E, Cristinelli L, et al.: Atherosclerotic renovascular disease: medical therapy versus medical therapy plus renal artery stenting in preventing renal failure progression: the rationale and study design of a prospective, multicenter and randomized trial (NITER). J Nephrol 2005, 18:423-428.

50. ASTRAL_Angioplasty and STent for Renal Artery Lesions. Available at: http://astral.bham.ac.uk. Accessed November 2002.

51. Cooper CJ, Murphy TP, Matsumoto A, et al.: Stent revascularization for the prevention of cardiovascular and renal events among patients with renal artery stenosis and systolic hypertension: rationale and design of the CORAL trial. Am Heart J 2006, 152:59-66. 